\title{
Factors Influencing the Decision to Have Child Among Iranian Couples; An Online Survey
}

\author{
Reza Jafarzadeh Esfehani $^{1^{\circledR}}$, Batool Kamalimanesh $^{2}{ }^{\circledR}$, Sareh Dashti $^{\left.{ }^{(}\right)}$, Ali Jafarzadeh Esfehani ${ }^{4^{*}}$
}

\begin{abstract}
Objectives: Total fertility rate (TFR) in Iran is declining to the lowest low level over the past 30 years. In order to increase the TFR, the influencing factors for willingness to have child should be identified. The aim of this study was to identify the factors that influence the willingness of Iranian men and women to have child.

Materials and Methods: This cross-sectional study was conducted on married Iranian men and women through an online survey. A questionnaire consisting of demographic characteristics, including age of subject, age of spouse, duration of marriage, number of children, education level of subjects and his/her spouse, current pregnancy status of subject or spouse, contraception use and type of contraception, and a validated questionnaire to identify the factors affecting willingness to have child in 4 domains (inter family factors, social factors, medical and parental factors and emotional and child related factors) were filled by subjects.

Results: A total of 731 subjects ( $23.1 \%$ male and $66.9 \%$ female) answered the online questions. Mean age of subjects was $31.80 \pm$ 6.83 years. Willingness to have child was significantly related to spousal age difference $(P=0.002$, odds ratio [OR] $=0.90)$, number of children $(P<0.001, \mathrm{OR}=0.21)$, being pregnant $(P<0.001, \mathrm{OR}=82.91)$, level of education in spouse $(P=0.03, \mathrm{OR}=2.18)$, inter family factors score $(P<0.001, \mathrm{OR}=1.14)$, social factors score $(P<0.001, \mathrm{OR}=0.87)$ and emotional and child related factors $(P<0.001$, $\mathrm{OR}=1.52$ ).

Conclusions: This study revealed that willingness to have child in Iranian men and women is mostly influenced by personal and spousal factors.

Keywords: Family, pregnancy, family planning services, Fertility, Decision to have child
\end{abstract}

\section{Introduction}

Total fertility rate (TFR) has been dropped globally in the past 50 years (1). For instance, TFR was 5 children per woman during 1950 to 1955 but this figure dropped to 2.8 children per woman in 2000 to 2005 (1). This decline in TFR was also reported in Asia, where the TFR has dropped from 6 to 2.3 children per woman (1).

Iran is among the countries in the Middle-East that experienced a dramatic decline in TFR during the past 3 decades, where the TFR dropped from 6.3 to 1.29 and was ranked first among the Asian countries in terms of TFR reduction $(1,2)$. It was shown that if the TFR stays below 1.3 for a long duration, there would be a fast decline in total population of the nation and thus results in increasing the elderly population, which in part reduces the productivity of the nation as well as increasing the costs of healthcare $(3,4)$.

Decision to have child is influenced by the knowledge and attitude of individuals regarding the consequences of having a child (2). Various influencing factors have been identified for fertility and decision to have child (4). Some of these factors include increased age of marriage, increased level of education of women, evolution of beliefs especially independence in women, increased values of the quality of life and quality of child raising compared to the number of children as well as economic issues and social support $(3,5,6)$.

To the best of knowledge, although no large populationbased study is available regarding the identification of the factors affecting decision to have child, assessing such factors among Iranian couples is important in order to increase the TFR. The internet penetration rate in Iran is reported to be $55 \%$, therefore, internet can be used to conduct nationwide studies at a low cost (7). Considering the definition of internet penetration rate, the percentage of a population who use internet, it can be hypothesized that more than half of the Iranian couples have access and use internet in their daily life, therefore, performing an online survey will provide an acceptable sample of Iranian couples. The aim of this study was to assess the factors that influence decision to have child among a sample of Iranian men and women based on an online survey.

\section{Materials and Methods}

In this cross-sectional study subjects were chosen from the internet users who gave written consent to participate 
in the study. The study questionnaire was compiled in Google Drive (www.google.com/forms/) and link to the survey page was provided in various groups in Telegram app. Subjects who were Iranian, married and were in child bearing age (18 to 47 years old for women and men). Subjects were excluded if they used definite contraception methods (Tubal legation or vasectomy). This internet survey only relied on participants self-reporting and the inclusion and exclusion of subjects was based on their reporting.

Prior to data collection for the study, a questionnaire was designed based on literature review. The primary questionnaire consisted of 19 questions. The questionnaire was then assessed for face and content validity by 5 experts and changes to the questionnaire were made. Then a semi qualitativeassessmentwasconducted on 84 menand women subjects through online link to check the acceptability of the interface as well as the content and comprehensibility of the items. Based on this assessment two more questions were added to the questionnaireresulting in a total of 21 items and final improvements were made to the online form of the questionnaire. The reliability and validity of the questionnaire were assessed in a pilot study on 100 subjects. The validity was assessed using exploratory factor analysis. Factor analysis revealed 4 domains in the questionnaire including inter family factors (7 items), social factors (7 items), medical and parental factors (4 items) and emotional and child related factors (3 items). The reliability of the questionnaire was assessed using the Cronbach's alpha which was acceptable (Cronbach's alpha $=0.94$ ).

In the data collection section of the study link to the questionnaire was shared in various Telegram channels and groups. Subjects who visited the questionnaire page were required to accept a consent form provided at the beginning of the survey. Subjects who did not consent to perform the survey were not permitted to fill the questionnaire. The questionnaire was designed in a way that subjects were only permitted to fill the questionnaire once. The questionnaire included two sections. The first section was designed to collect demographic information including age of subject, age of spouse, duration of marriage, number of children, education level of subjects and his/her spouse, current pregnancy of subject or spouse, contraception use and type of contraception and willingness to have child. Second section of the questionnaire included the willingness to have child questionnaire that consisted of 21 questions. Subjects were required to rate each question based on a liker scale from 0 (indicating strongly disagree) to 5 (indicating strongly agree). Scores were calculated for each domain by summing up the scores of each question in the domain (Table 1). The questionnaire included an open-ended question that would let the subjects add other reasons they might have for willingness or unwillingness to have child.
Table 1. Domains of the Willingness to Have Child Questionnaire

\begin{tabular}{ll}
\hline Domain & Questions \\
\hline & Spouse Likes boy we have girl \\
& Spouse likes girl we have boy \\
& Willingness of greater child \\
Inter family factors & Old age of subject/spouse \\
& Different gender from previous child \\
& Failure to raise previous child properly \\
& Loss of child \\
& Insure others of fertility \\
& Governmental aids \\
& Benefits of maternity leave \\
Culture and religion \\
Focial factors & Sashion \\
Solve family problems \\
Increase family income in future \\
Parental pressure \\
In-law pressure \\
Insure oneself of fertility \\
Medical problems \\
Desire to have child \\
Happiness and completion \\
Bactors
\end{tabular}

\section{Statistical Analysis}

Data analysis was performed using the Statistical Package for Social Sciences (SPSS) software version 21 (IBM, Inc, Chicago, Il, USA). Continuous data were checked for normality using the Kolmogorov-Smirnov test. Mean and standard deviation (SD) were used for normality distributed data while median and interquartile range (IQR) were used for non-normally distributed data. Frequency and percentage were used for categorical data. Independent sample $t$ test was used for comparison of continuous data between study groups (subjects who were willing to have child and those who did not want child) for both normally and non-normally distributed data due to the large sample size. It was previously shown that parametric tests are more acceptable for large sample sizes compared to non-parametric tests, therefore the independent $t$ test was used for the comparison (8). Association between categorical variables and willingness to have child was assessed using the chi-square and Fisher exact tests. Relationship between willingness to have child and study variables was assessed using binary logistic regression with willingness to have child as dependent variable and other variables as independent variables. The odds ratio (OR) and 95\% confidence interval (CI) for OR were shown. In order to assess the relationship between type of contraceptive and willingness to have child, types of contraceptive were dichotomized into rapid reversible methods, including natural and condom use, and slow reversible, including intra uterine device (IUD) and oral contraceptive pill (OCP) and the relationship between 
type of contraceptive and willingness to have child was assessed using binary logistic regression. The $P$ value $<$ 0.05 were considered significant.

\section{Results}

A total of 731 subjects (169, 23.1\% male and 562, 66.9\% female) agreed to participate in the study. Mean age of subjects was $31.80 \pm 6.83$ years, median and IQR for age difference between spouses were 4.00, 4.00 years respectively. Median and IQR for number of children among subjects were 0.00 and 1.00 respectively and the median and IQR for marriage duration were 5.00 and 6.00 years respectively. Demographic characteristics of study subjects are shown in Table 2.

Among the study subjects 507 (69.4\%) were pregnant or willing to have child. There was a significant difference between subjects who were willing to have child and those who did not want child in terms of number of children $\mathrm{t}(711)=9.20, P<0.001$, marriage duration $\mathrm{t}(729)=5.38$, $P<0.001$, gender $\chi^{2}(1, \mathrm{~N}=731)=19.51, P<0.001$, subjects who were currently pregnant $(P<0.001$, Fisher exact test $)$ and contraception use $\chi^{2}(2, \mathrm{~N}=731)=29.05, P<0.001$ (Table 2).

Based on the willingness to have child questionnaire responses, there was a significant difference between subjects who were willing to have child and those who did not want to have child in terms of interfamily factors scores t $(729)=-14.86, P<0.001$, social factors scores t (729) $=-3.64, P<0.001$, medical and parental factors scores $\mathrm{t}(729)=-8.49, P<0.001$ and emotional and child related factors scores $\mathrm{t}(729)=-16.01, P<0.001$ (Table 3 ).

Binary logistic regression revealed that willingness to have child was significantly related to spousal age difference $(P=0.002, \quad \mathrm{OR}=0.90)$, number of children $(P<0.001$, $\mathrm{OR}=0.21)$, being pregnant $(P<0.001, \mathrm{OR}=82.91)$, level of education in spouse $(P=0.03, \mathrm{OR}=2.18)$, inter family factors score $(P<0.001, \mathrm{OR}=1.14)$, social factors score $(P<0.001, \mathrm{OR}=0.87)$ and emotional and child related factors score $(P<0.001, \mathrm{OR}=1.52)$ (Table 4$)$.

A sub-analysis was performed on subjects who reported to use contraceptives. No significant relationship was found between type of contraceptive use and willingness

Table 2. Demographic characteristics of study subjects as per study groups

\begin{tabular}{|c|c|c|c|c|}
\hline & $\begin{array}{c}\text { Total } \\
\mathrm{N}=731\end{array}$ & $\begin{array}{l}\text { Willing to Have Child } \\
\qquad n=507\end{array}$ & $\begin{array}{l}\text { Unwilling to Have Child } \\
\qquad n=224\end{array}$ & $P$ Value \\
\hline Age (y) & $31.80 \pm 6.83 \dagger$ & $31.67 \pm 6.27 \dagger$ & $32.02 \pm 7.91 \dagger$ & 0.55 \\
\hline Spousal age difference (y) & $4.00(4.00) \ddagger$ & $4.00(4.00) \ddagger$ & $4.00(5.00) \ddagger$ & 0.86 \\
\hline Number of children & $0.00(1.00) \ddagger$ & $0.00(1.00) \mp$ & $1.00(2.00) \mp$ & $<0.001^{*}$ \\
\hline Marriage duration (y) & $5.00(6.00) \ddagger$ & $5.00(5.00) \ddagger$ & $6.00(8.50) \ddagger$ & $<0.001^{*}$ \\
\hline Gender & & & & $<0.001^{*}$ \\
\hline Male & $169(100 \%)$ & $94(55.6 \%)$ & 75 (44.4\%) & \\
\hline Female & $562(100 \%)$ & $413(73.5 \%)$ & $149(26.5 \%)$ & \\
\hline Place of living & & & & 0.55 \\
\hline Urban & 715 (100\%) & 497 (69.5\%) & $218(30.5 \%)$ & \\
\hline Rural & $16(100 \%)$ & $10(62.5 \%)$ & $6(37.5 \%)$ & \\
\hline Currently pregnant & 90 (100\%) & 89 (98.9\%) & $1(0.1 \%)$ & $<0.001 * ¥$ \\
\hline Level of education of subject & & & & 0.43 \\
\hline Under graduate & $136(100 \%)$ & $99(72.8 \%)$ & $37(27.2 \%)$ & \\
\hline Graduate & 337 (100\%) & $236(70.0 \%)$ & $101(30.0 \%)$ & \\
\hline Postgraduate & $258(100 \%)$ & $172(66.7 \%)$ & $86(33.3 \%)$ & \\
\hline Level of education of spouse & & & & 0.64 \\
\hline Under graduate & $184(100 \%)$ & $127(69.0 \%)$ & $57(31 \%)$ & \\
\hline Graduate & 321 (100\%) & $228(71.0 \%)$ & $93(29 \%)$ & \\
\hline Postgraduate & $226(100 \%)$ & $152(67.3 \%)$ & $74(32.7 \%)$ & \\
\hline Contraception use & $441(100 \%)$ & $273(61.9 \%)$ & $168(38.1 \%)$ & $<0.001 *$ \\
\hline Type of contraception & & & & 0.40 \\
\hline $\mathrm{OCP}$ & $57(100 \%)$ & $36(63.2 \%)$ & $21(36.8 \%)$ & \\
\hline IUD & $16(100 \%)$ & $7(43.7 \%)$ & $9(56.3 \%)$ & \\
\hline Condom & 191 (100\%) & $123(64.4 \%)$ & $68(35.6 \%)$ & \\
\hline Natural & 177 (100\%) & 107 (60.4\%) & $70(30.6 \%)$ & \\
\hline
\end{tabular}

${ }^{+}$Mean and standard deviation (SD) were used.

${ }^{\ddagger}$ Median and Interquartile range (IQR) were used.

Due to the large number of subjects, independent t-test was used for comparison of continuous variables (age, spousal age difference, number of children and marriage duration) regardless of normality.

${ }^{¥}$ The $\chi^{2}$ test was used to assess the relationship between willingness to have child and all categorical variables except for currently pregnant variable, where the Fisher's exact test was used.

* Significant at $\alpha=0.05$ 
Table 3. Scores in Willingness to Have Child Questionnaire Domains as Per Study Groups

\begin{tabular}{lccc}
\hline & Total & Willing to Have Child & Unwilling to Have Child \\
\hline Inter family factors & $16.24 \pm 6.47$ & $18.46 \pm 5.07$ & $11.20 \pm 6.49$ \\
Social factors & $10.92 \pm 5.93$ & $11.46 \pm 5.81$ & $<.72 \pm 6.02$ \\
Medical and parental factors & $8.11 \pm 4.56$ & $8.98 \pm 4.55$ & $6.16 \pm 3.94$ \\
Emotional and child related factors & $9.73 \pm 4.00$ & $11.25 \pm 2.77$ & $<.29 \pm 4.23$ \\
\hline
\end{tabular}

Due to the large number of subjects, independent t-test was used for comparison of continuous variables (age, spousal age difference, number of children and marriage duration) regardless of normality.

* Significant at $\alpha=0.05$

Table 4. Relationship Between Study Variables and Willingness to Have Child

\begin{tabular}{|c|c|c|c|c|c|}
\hline & \multirow{2}{*}{ Wald } & \multirow{2}{*}{ Sig. } & \multirow{2}{*}{ OR } & \multicolumn{2}{|c|}{$95 \% \mathrm{Cl}$ for OR } \\
\hline & & & & Lower & Upper \\
\hline Gender (male) & 0.03 & 0.86 & 0.95 & 0.52 & 1.73 \\
\hline Age & 1.35 & 0.25 & 1.02 & 0.99 & 1.06 \\
\hline Spousal age difference & 9.28 & $0.002^{*}$ & 0.90 & 0.83 & 0.96 \\
\hline Number of Children & 41.94 & $<0.001^{*}$ & 0.21 & 0.13 & 0.34 \\
\hline Pregnancy & 14.59 & $<0.001^{*}$ & 82.91 & 8.59 & 799.80 \\
\hline Marriage duration & 1.11 & 0.29 & 1.03 & 0.97 & 1.09 \\
\hline \multicolumn{6}{|l|}{ Level of education of subject (undergraduate) } \\
\hline Level of education (graduate) & 1.30 & 0.25 & 0.63 & 0.29 & 1.39 \\
\hline Level of education (post graduate) & 1.32 & 0.25 & 0.58 & 0.23 & 1.47 \\
\hline \multicolumn{6}{|l|}{ Level of education of spouse (under graduate) } \\
\hline Level of education of spouse (graduate) & 4.95 & $0.03^{*}$ & 2.18 & 1.10 & 4.33 \\
\hline Level of education of spouse (post graduate) & 2.38 & 0.12 & 1.88 & 0.84 & 4.20 \\
\hline Contraception & 0.60 & 0.44 & 0.80 & 0.45 & 1.41 \\
\hline Inter family factors & 24.53 & $<0.001^{*}$ & 1.14 & 1.08 & 1.20 \\
\hline Social factors & 20.57 & $<0.001^{*}$ & 0.87 & 0.82 & 0.92 \\
\hline Medical and parental factors & 0.06 & 0.80 & 0.99 & 0.91 & 1.08 \\
\hline Emotional and child related factors & 88.09 & $<0.001^{*}$ & 1.52 & 1.39 & 1.66 \\
\hline
\end{tabular}

Level of education of subject (undergraduate) and level of education of spouse (undergraduate) were selected as reference category in the regression analysis.

* Significant at $\alpha=0.05$

to have child among subjects who reported to use contraceptives $(P=0.67)$.

\section{Discussion}

This internet survey revealed that more than two third of the participants were willing to have child. Willingness to have child was significantly related to spousal age difference, number of children, level of education in spouse, inter family, social, emotional and child related factors score. To the best of our knowledge few studies have been conducted in Iran regarding the decision to have child and its influencing factors (9-11). These studies were performed either on a small sample size or in a single geographical region. Geographical distance and financial restrictions are among the barriers to perform nationwide studies. On the other hand, internet can be considered as a solution to geographical barriers in conducting studies. In a previous study conducted on 360 Iranian mothers, $5.6 \%$ of the mothers were willing to have another child (9). The difference between the findings of current study and the reported willingness of having child may be due to the fact that the current study included both genders as well as couples who did not have a child. In another study that was conducted on 380 Iranian men and women of childbearing age, $84.8 \%$ of subjects reported to have low to moderate willingness to have child (10). Difference in the definition of willingness to have child may be a possible cause of their higher rate in contrast to our study. In this study willingness was dichotomized as willing or not willing while the study by Piltan et al reported willingness as a scale, therefore the moderate willingness could be categorized as willingness and the percentage would increase. It was previously shown that parents who have one child are less willing to have another child in the first 7 years after the birth of the first child due to the difficulties in raising children below the age of 7 years (9). Therefore, the difference in the findings of the study by Piltan et al and the current study might be due to the reduced willingness of parents who have one child below 5 years of age.

This study revealed that significantly more women were willing to have child compared to men. It was previously 
shown that women postpone pregnancy due to the drawbacks of early pregnancy regarding their academic and economic achievements (12). As the mean age of the subjects in this study was 31.8 years old and most of the subjects had post-secondary education, women subjects may not have any reason to postpone their pregnancy and therefore the rate of willingness to have child was higher in women compared to men. On the other hand, the findings of the current studywas in contrast with the finding of the study by Piltan et al who reported no gender differences in terms of willingness to have child. The difference between the findings of the current study and the study by Piltan et al might be due to the unequal number of men and women in the current study compared to the equal number of men and women in the study by Piltan et al (10). As the logistic regression analysis failed to identify any gender differences in the odds of willing to have child, the observed gender difference in willingness to have child might be due to the higher percentage of women in the study.

The current study also revealed that participants who were willing to have child were using more means of contraception compared to those who did not want a child. It was previously shown that feeling of unpreparedness regarding oneself or the spouse may act as a delaying factor in decision to have a child $(6,13)$.

Regression analysis revealed a significant inverse relationship between willingness to have child and spousal age difference $(\mathrm{OR}=0.90)$ indicating that 1 -year increase in age difference of the couples was associated with $90 \%$ less likelihood of willingness to have child. In other words, large age difference between couples is associated with reduced $t$ likelihood of affinity to have a child. It was previously shown that the increase in age would result in increased willingness to have child especially among women $(12,14)$. In contrast, another study showed that due to the mind-set women designed for their ideal number of children to be achieved at older age (30-35 years old) $(15,16)$. Since the median observed spousal age difference in the current study was 4 years and that most of the subjects were women, they might also have a mindset to complete their family size when they are between 30 to 35 years old.

Furthermore, regarding the lack of significant relationship between subjects' age and willingness to have child, this reduced willingness might be related to the subjects who had one child and are under the influence of hardships of growing an infant or toddler. This study also found that number of children resulted in significant reduction in the odds of willingness to have children. As previously stated, this finding was in line with the findings of a previous study on Iranian subjects (9). Furthermore, the current study found a significant relationship between spousal education level and willingness to have child, indicating that subjects with spouses who were in graduate level of education were 2.18 times more likely to be willing to have child. This finding might indicate that subjects who have a higher level of education have better opportunities to be employed in well paid jobs and therefore will have fewer financial problems in raising a child. Previous studies have also found a positive relationship between level of education and willingness to have child $(6,12,17)$.

Among the domains of willingness to have child questionnaire inter family factors score $(\mathrm{OR}=1.14)$, social factors score $(\mathrm{OR}=0.87)$ and emotional and child related factors score $(\mathrm{OR}=1.52)$ were found to be significantly related to willingness to have child. Emotional and child related factors were found to have the most powerful influence on willingness to have child. This domain included the desire to have child, happiness and sense of completion with having a child and desire to have a big family. All these factors were previously found to be great motivators to have child both in women and men $(6,10$, 12). Interfamily factors domain included the desire to have children of different gender, willingness or pressure of greater children to have brothers or sisters, old age, loss of child and failure to raise the previous child in a good way. Although the desired number of children were not asked in this study, this domain indirectly indicates that subjects were willing to have more than one child with different genders. This finding wasin consistence with the findings of Piltan et al (10). Old age was another factor that was discussed earlier. Although no significant association was observed between the age of subjects and willingness to have child, considering the increased age and the consequences of pregnancy postponement might be a reason for willingness to have a child. It was also shown that due to the increased age of marriage and delayed pregnancy due to economic and financial reasons, couples will decide to have child at an older age $(6,10,12)$. In a qualitative study on 22 women and 18 men revealed that determining the perfect age for pregnancy relates to their reproductive capacity and financial stability while some of the respondents stated that they may never be able to be perfect to have a child (18).

In contrast to other domains, the social factors were found to be inversely related to willingness to have child. This domain included the cultural and religious reasons, governmental aids and incentives, maternity leave, solving family problems and increasing family income in future as well as showing others that they can have a child. In the study by Piltan et al religious reasons were found to be significantly related with increasing willingness to have child (10). Unlike the study by Piltan et al, the current study revealed negative effect for religious and cultural factors on willingness to have child. It was shown that current tendency toward child raising is more focused on quality of raising compared to the past (12). This obsession for perfection has resulted in postponement of pregnancy as well as reducing the number of children that couples 
plan to have in future (12). This finding might also be related to the suppression of religious and cultural beliefs by the obsession for perfection. Governmental support is considered a powerful factor in decision to have child $(6,12)$. A reason for the paradox between the current study and the previous studies might be due to the high level of education of subjects in the current study. Higher education is associated with better jobs and the subjects might not feel dependent to governmental support or incentives or they might find those aids insufficient, as one of the subjects compared governmental incentives to "decoy". Increasing future income and proving one's fertility to others were considered as influencing factors for willingness to have child in the past but recent data suggest no important role for these factors $(6,12)$.

The current study found no significant relationship between medical and parental factors and willingness to have child. It was previously shown that pressure form parents might have a role in decision to have child $(6,12)$. In contrast it was also shown that by increasing the age of couples they consider themselves as independent and mature adults who decide for their family themselves ( 6 , 12). Regarding the age of the subjects in the current study and the education level of subjects, independent decision making might be the reason for the lack of relationship between parental factors and willingness to have child. Besides due to the small number of subjects with medical condition that requires prompt pregnancy, this factor might have had no effect on the willingness to have child.

To the best of our knowledge this study was the largest study conducted on Iranian population with the aim of determining the factors that influence the willingness to have child. Another strength of this study was the online data collection method, which provided a selection of subjects from various backgrounds and regions. One of the weaknesses of this study was participation of urban subjects in the study as well as subjects with higher education levels, which is related to their ability to use internet. Therefore, the findings of this study might not be generalized to the whole Iranian population. Further researches are required to assess other socio-economic classes of the society.

One of the weaknesses of this study was participation of urban subjects in the study as well as subjects with higher education levels, which is related to their ability to use internet. Therefore, the findings of this study might not be generalizable to the whole Iranian population. Further researches are required to assess other socio-economic classes of the society. Moreover, internet surveys relay on self-reporting of data and we have trusted the participants input data as is. Further researchers can be conducted on specific population in our country while some of the influencing factors take effect from cultural and economic factors in each region.

\section{Conclusions}

This study revealed that the emotional and child related factors were the most influential factors on willingness to have a child followed by inter family factors and that social factors had a negative effect on willingness to have child. The findings of this study may help health care providers in planning interventions to minimizing the negative effectors in order to increase childbearing willingness in the country.

\section{Conflict of Interests}

Authors declare that they have no conflict of interests.

\section{Ethical Issues}

The Ethical Committee of the Sabzevar University of Medical Sciences approved this study (Registration code: Medsab.Rec.93.119).

\section{Financial Support}

None.

\section{Acknowledgments}

The authors would like to thank all the participants who devoted their time to complete the questionnaire.

\section{References}

1. Gubhaju B. Fertility transition and population ageing in the Asian and Pacific region. Asia Pacific Population Journal. 2008 Aug; 23(2):55-80.

2. Kaboudi M, Ramezankhani A, Manouchehri H, Hajizadeh E, Haghi M. The decision-making process of childbearing: a qualitative study. Payesh. 2013;12(5):505-515.

3. Hajikhani NA, Ozgoli G, Pourebrahim T, Mehrabi Y, Khoori E. Characterizing mental health status of couples in high-risk pregnancy and its relevant characteristics. Int J Womens Health Reprod Sci. 2018;6(4):465-470. doi: 10.15296/ijwhr.2018.77.

4. Ahmadi S, Rahmani E, Motamed N, Sadeghi F. Investigating the success rate of sex selection in cycles of intrauterine insemination of sperm using an albumin gradient method in infertile couples referring to the Omid Persian Gulf Infertility Center of Bushehr, Iran. Int J Womens Health Reprod Sci. 2017;5:107-11. doi: 10.15296/ijwhr.2017.20.

5. Blyth E. Below population replacement fertility rates: Can assisted reproductive technology (ART) help reverse the trend? Asian Pacific Journal of Reproduction 2013; 2: 1518. doi: 10.1016/S2305-0500(13)60137-2

6. Mills M, Rindfuss RR, McDonald P, Te Velde E. Why do people postpone parenthood? Reasons and social policy incentives. Hum Reprod Update 2011; 17: 848-60. doi: 10.1093/humupd/dmr026

7. Dashti S, Peyman N, Tajfard M, Esmaeeli H. E-Health literacy of medical and health sciences university students in Mashhad, Iran in 2016: a pilot study. Electron Physician 2017; 9: 3966-73. doi: 10.19082/3966

8. Kitchen CM. Nonparametric vs parametric tests of location in biomedical research. Am J Ophthalmol. 2009; 147: 5712. doi: 10.1016/j.ajo.2008.06.031 
9. Sadeghi S, Saraie H. Effective Factors on Mothers' Inclination to Have Children in Tehran Hannaneh Sadat Sadeghi, Hasan Saraie. Social Development \& Welfare Planning 2016; 7: 1-32. doi: 10.22054/qjsd.2016.5920

10. Piltan F, Rahmanian M. Investigating factors affecting the tendency toward childbearing among married men and women (case of study: men and women aged 25 to 45 years old in Jahrom). Journal of Iranian Social Development Studies. 2015;7(2):121-134.

11. Ebrahimpoor M, Ebadi S. Generational Differences and Preferences in Childbearing in the city of Sari (opinions and attitudes). Journal of Population Association of Iran. 2014; 8: 55-78.

12. Balbo N, Billari FC, Mills M. Fertility in advanced societies: A review of research. Eur J Popul. 2013; 29: 1-38. doi: 10.1007/s10680-012-9277-y

13. Benzies K, Tough S, Tofflemire K, Frick C, Faber A, Newburn-Cook C. Factors influencing women's decisions about timing of motherhood. Journal of Obstetric, Gynecologic \& Neonatal Nursing 2006; 35: 625-33. doi: 0.1111/j.1552-6909.2006.00079.x
14. Miller EA, West DM. Where's the revolution? Digital technology and health care in the internet age. J Health Polit Policy Law. 2009; 34: 261-84. doi: 10.1111/j.17284457.2011.00411.x

15. Skoog Svanberg A, Lampic C, Karlstrom PO, Tyden T. Attitudes toward parenthood and awareness of fertility among postgraduate students in Sweden. Gend Med 2006; 3: 187-95. doi: 10.1016/S1550-8579(06)80207-X

16. Maheshwari A, Porter M, Shetty A, Bhattacharya S. Women's awareness and perceptions of delay in childbearing. Fertil Steril 2008; 90: 1036-42. doi: 10.1016/j. fertnstert.2007.07.1338

17. Sobotka T, editor. Economic recession and fertility in the developed world: Past evidence and recent trends. Population and Development Review. 2011;37:267-306. doi:10.1111/j.1728-4457.2011.00411.x

18. Eriksson C, Larsson M, Tydén T. Reflections on having children in the future--interviews with highly educated women and men without children. Upsala Journal of Medical Sciences 2012; 117: 328-35. doi: $10.3109 / 03009734.2012 .654862$

(c) 2019 The Author (s); This is an open-access article distributed under the terms of the Creative Commons Attribution License (http://creativecommons.org/licenses/by/4.0), which permits unrestricted use, distribution, and reproduction in any medium, provided the original work is properly cited. 